\title{
Glutathione and Homoglutathione Play a Critical Role in the Nodulation Process of Medicago truncatula
}

\author{
Pierre Frendo, Judith Harrison, Christel Norman, María Jesús Hernández Jiménez, Ghislaine Van de \\ Sype, Alain Gilabert, and Alain Puppo
}

Interactions Plantes-Microorganismes et Santé Végétale, UMR CNRS-INRA-Université de Nice-Sophia Antipolis, 400, Route des Chappes, BP167, 06903 Sophia-Antipolis Cedex, France

Submitted 6 August 2004. Accepted 1 November 2004.

\begin{abstract}
Legumes form a symbiotic interaction with bacteria of the Rhizobiaceae family to produce nitrogen-fixing root nodules under nitrogen-limiting conditions. This process involves the recognition of the bacterial Nod factors by the plant which mediates the entry of the bacteria into the root and nodule organogenesis. We have examined the importance of the low molecular weight thiols, glutathione (GSH) and homoglutathione (hGSH), during the nodulation process in the model legume Medicago truncatula. Using both buthionine sulfoximine, a specific inhibitor of GSH and hGSH synthesis, and transgenic roots expressing GSH synthetase and hGSH synthetase in an antisense orientation, we showed that deficiency in GSH and hGSH synthesis inhibited the formation of the root nodules. This inhibition was not correlated to a modification in the number of infection events or to a change in the expression of the Rhizobium sp.-induced peroxidase rip1, indicating that the low level of GSH or hGSH did not alter the first steps of the infection process. In contrast, a strong diminution in the number of nascent nodules and in the expression of the early nodulin genes, Mtenod12 and Mtenod40, were observed in GSHand hGSH-depleted plants. In conclusion, GSH and hGSH appear to be essential for proper development of the root nodules during the symbiotic interaction.
\end{abstract}

The interaction between legumes and rhizobial bacteria leads to the formation of a new specialized organ, the nodule, that is capable of fixing atmospheric nitrogen. The first visible signs of the symbiotic interaction are the deformation and curling of root hairs. Within the curled root hairs, rhizobia promote the formation of plant-derived infection threads that contain the bacteria. At the same time, the cortical cells below the infection threads begin to divide and form the nodule primordium. The infection threads allow the transport of the bacteria from the outer surface of the root into the nodule primordium (Cohn et al. 1998; Mylona et al. 1995).

Cross-talk between the plant and the bacteria is essential for the establishment of the symbiosis. In a first step, plant signal

Corresponding author: A. Puppo; E-mail: puppo@unice.fr; Fax: (33) 492 386640 .

Pierre Frendo and Judith Harrison contributed equally to this work.

Current address of J. Harrison: Centre for Research in Plant Science, University of West of England, Cold Harbor Lane, Bristol, BS16 1QY, U.K.

Current address of C. Norman: Plant Molecular Biology Group, Department of Biochemistry, University of Western Australia, 35 Stirling Hwy, Crawley, WA 6009, Australia. molecules induce the biosynthesis of bacterial lipochitooligosaccharides which are termed Nod factors (Dénarié and Cullimore 1993). Nod factors act as signaling molecules and initiate nodule formation. Indeed, purified Nod factors are able to elicit root hair deformation, induction of early nodulin (enod) genes specifically induced during the early steps of nodulation, and initiation of cortical cell division (Crespi et al. 1994; Journet et al. 1994).

Glutathione (GSH) is the major low molecular weight thiol in plants. It is involved in the plant antioxidant defence, the detoxification of xenobiotics, and the tolerance to abiotic and biotic stresses (May et al. 1998; Noctor et al. 1998). In certain legumes, a GSH homolog, homoglutathione (hGSH), also is present instead of or in addition to GSH (Frendo et al. 1999; Klapheck 1988; Matamoros et al. 1999). The high level of GSH or hGSH in root nodules and the presence of an active ascorbate-GSH cycle suggest that GSH and hGSH are involved in the protection of the nitrogen-fixing nodules against toxic oxygen species resulting from the active nodule metabolism (Becana et al. 2000; Dalton et al. 1986). Synthesis of GSH and hGSH is a two-step process. In the first step, $\gamma$-glutamylcysteine synthetase $(\gamma$-GCS) produces the dipeptide $\gamma$-glutamylcysteine $(\gamma-\mathrm{GC})$ from L-glutamic acid and L-cysteine. The formation of GSH and hGSH is determined by the substrate specificity of the enzyme catalyzing the second step. Glutathione synthetase (GSHS; E.C. 6.3.2.3) catalyses the addition of glycine to $\gamma$ GC, whereas homoglutathione synthetase (hGSHS; E.C. 6.3.2.23) catalyses the addition of $\beta$-alanine to $\gamma$-GC.

Although it appears that GSH and hGSH are important in the nitrogen-fixing nodule, the role of GSH and hGSH during the first steps of nodulation has not, to our knowledge, been investigated. GSH has been shown to be involved in plantpathogen interactions as well as in the induction of plant defense genes (Vanacker et al. 2000; Wingate et al. 1988). In this context, studies have shown that $90 \%$ of the infection threads aborted during the establishment of the symbiosis in Medicago plants, a phenomenon which is connected to a hypersensitive response (Penmetsa and Cook 1997; Vasse et al. 1993). Moreover, the nodulation process involves the reinitiation of cell division to establish nodule primordia and GSH has been shown to participate in the initiation and the regulation of cell division in apical meristem of Arabidopsis roots (Sanchez-Fernandez et al. 1997; Vernoux et al. 2000). Such evidence suggests that GSH may have an important role in different aspects of the plant-bacteria interaction.

In this study, we show that inhibition of GSH and hGSH synthesis either by L-buthionine-[S-R]-sulfoximine (BSO), a specific inhibitor of $\gamma$-GCS, or by expressing either GSHS or hGSHS genes in antisense orientation in roots, resulted in a 
reduction of the average number of nodules in inoculated roots. Moreover, we show that the inhibition of GSH and hGSH synthesis reduces the expression of genes involved in the nodulation process without affecting physiological and molecular markers of the first steps of infection.

\section{RESULTS}

\section{GSH and hGSH deficiency results}

in a lower number of nodules.

In order to investigate the involvement of the GSH and hGSH pool in the Medicago truncatula-Sinorhizobium meliloti symbiosis, two strategies aimed at modifying the GSH an hGSH pool were developed. In a first approach, M. truncatula seedlings were germinated and grown on BSO, a specific inhibitor of $\gamma$-ECS used already in plants (Sanchez-Fernandez et al. 1997). To determine the concentration of BSO required to decrease the level of GSH in $M$. truncatula, seedlings were germinated and grown on different concentrations of BSO. GSH is involved in the plant protection against heavy metal; therefore, cadmium was used as a biological test to measure the effect of BSO on the GSH and hGSH pool. A concentration of $0.1 \mathrm{mM}$ BSO did not modify the growth of the plants (Fig. 1A); whereas, at higher BSO concentrations, plant growth was significantly affected. The presence of $0.1 \mathrm{mM}$ cadmium in the growth medium concomitantly with BSO treatment strongly affected the growth of the plants regardless of the BSO concentration used (Fig. 1A). In 9-day-old plants, high-performance liquid chromatography (HPLC) analysis of the GSH or hGSH content in the $0.1 \mathrm{mM}$ BSO-treated plants showed that the concentration of $\mathrm{GSH} / \mathrm{hGSH}$ in the roots was reduced by $85 \%$ (from $385 \pm 38$ $\mathrm{nmol} / \mathrm{g}$ fresh weight to $57 \pm 13 \mathrm{nmol} / \mathrm{g}$ fresh weight) after treatment. This GSH and hGSH pool deficiency was maintained during the time course of the experiments. No significant difference in the number of lateral roots was observed between 9-day-old plants treated or not treated with BSO, and the root tip, root hair development zone, and mature root were not modified (Fig. 1B). This concentration was chosen to further analyze the implication of GHS or hGSH in the nodulation process.

BSO-treated plants were inoculated with $S$. meliloti strain RCR2011 and the number of nodules formed was assessed. BSO-treated plants also formed fewer nodules than control plants, a reduction which was visible both 7 and 10 days postinoculation (Fig. 1C). Treatment of the BSO-treated plants with $0.5 \mathrm{mM} \mathrm{GSH}$ results in the full restoration of the nodulation efficiency. A significant reduction in the number of lateral roots in the BSO-treated plants also was observed compared with the control plants with or without bacterial inoculation. However, the number of nodules on the primary root of control

Fig. 1. Plant development and nodulation during L-buthionine-[S-R]sulfoximine (BSO) treatment. A, Plants were germinated and grown on modified Farhaeus medium containing increasing concentration of BSO, with cadmium $(+\mathrm{Cd})$ or without cadmium $(-\mathrm{Cd})$. Fresh weight was measured 9 days after germination; * and ** indicates difference at $P<$ 0.05 and $<0.001$, respectively. B, Root development during BSO treatment. After 2 days of germination, plants were grown on modified Farhaeus medium (control) and modified Farhaeus medium containing 0.1 mM BSO (BSO) for one week. Root tip (1), root hair development zone (2), and mature root (3) are represented. Bars represent $20 \mu \mathrm{m}$. C, Plants were grown on modified Farhaeus medium (control plants), modified Farhaeus medium containing $0.1 \mathrm{mM}$ BSO (BSO-treated plants) for 1 week, and modified Farhaeus medium containing $0.1 \mathrm{mM}$ BSO and 0.5 $\mathrm{mM}$ glutathione (complemented plants) and inoculated with Sinorhizobium meliloti RCR2011. The total number of nodules was assessed 7 (7T) and 10 (10T) days postinoculation. The number of nodules present on the primary root was also counted 10 days postinoculation $(10 \mathrm{P}) ; *$ indicates significant difference (at least $P<0.05$ ). plants was significantly higher than on the primary root of BSO-treated plants (Fig. 1C). The acetylene reduction assay performed on BSO-treated plants showed that the nodules were able to fix nitrogen.

In parallel with the BSO treatment, a genetic approach also was developed. Individual transgenic roots expressing GSHS

A

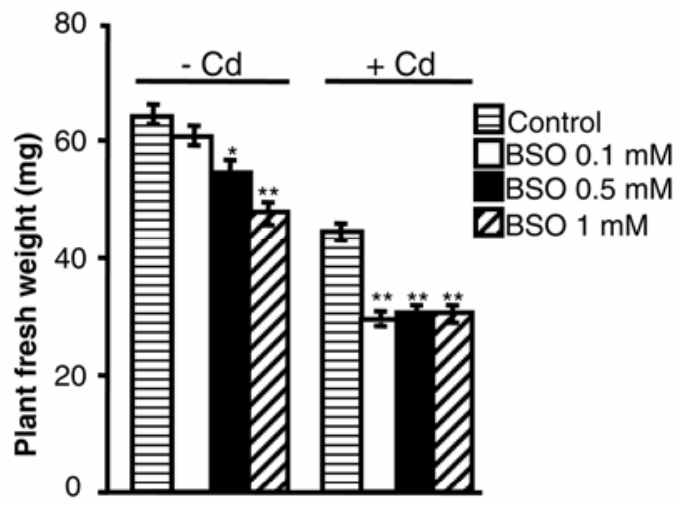

B
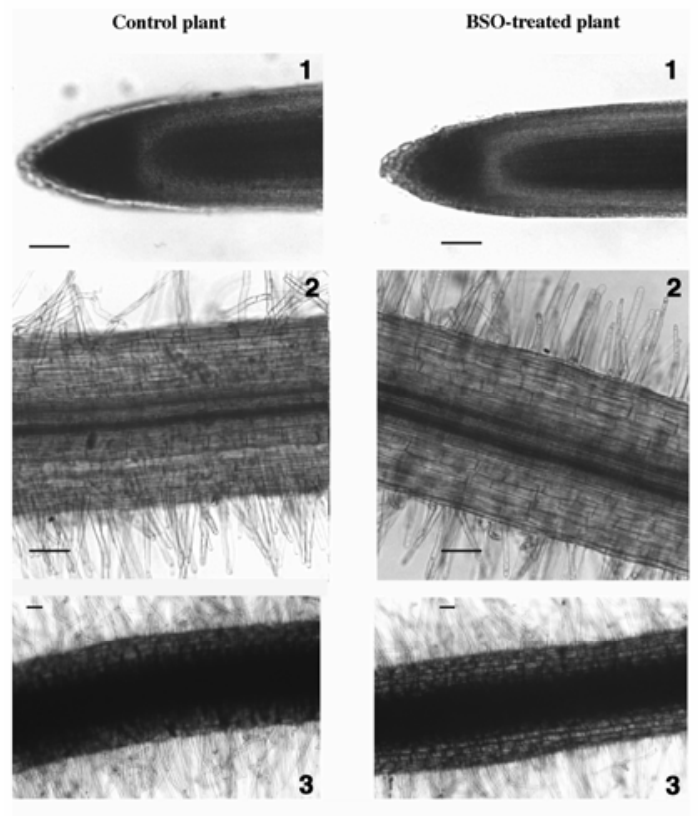

C

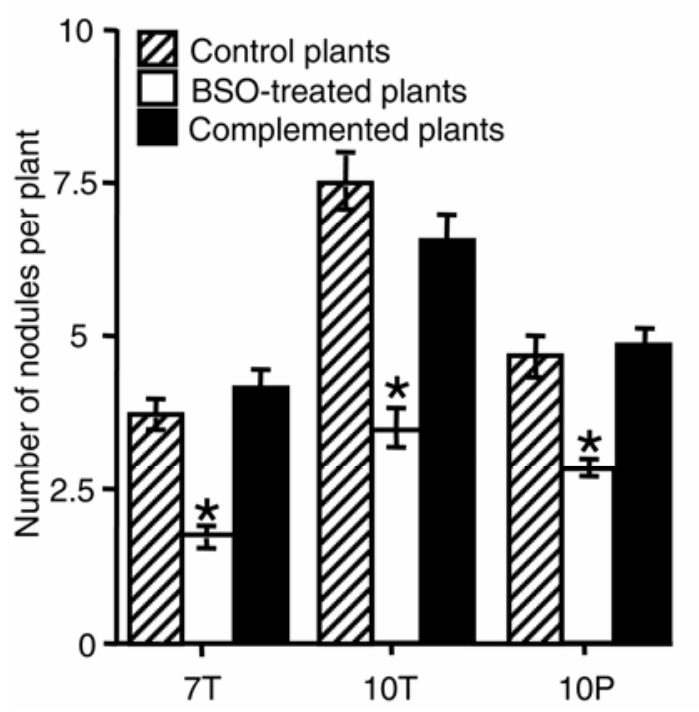

Vol. 18, No. 3, 2005 / 255 
(construct pBI121-ASGSHS) and hGSHS (construct pBI121AShGSHS) in antisense orientation under the control of the Cauliflower mosaic virus $35 \mathrm{~S}$ promoter were produced. The thiol concentration of nodulated roots transformed with pBI121-ASGSHS and pBI121AShGSHS constructs was compared with the thiol concentration of control-nodulated roots transformed with the empty vector (Fig. 2A). In control roots, the concentrations of GSH and hGSH were of the order of 65 nmoles/g fresh weight, whereas $\gamma$-GC never was present at a concentration greater than 2 to 3 nmoles/g fresh weight. Eight individual roots transformed with pBI121-ASGSHS presented a modification in their thiol concentration. A diminution in both GSH and hGSH was observed in these roots, indicating that the construct was not specific for GSHS (Fig. 2A, plants AS-GS). The decrease in the concentration of GSH and hGSH was accompanied by a strong increase in the $\gamma$-GC content. A stronger diminution in the concentration of hGSH was observed in 10 individual roots transformed with pBI121-
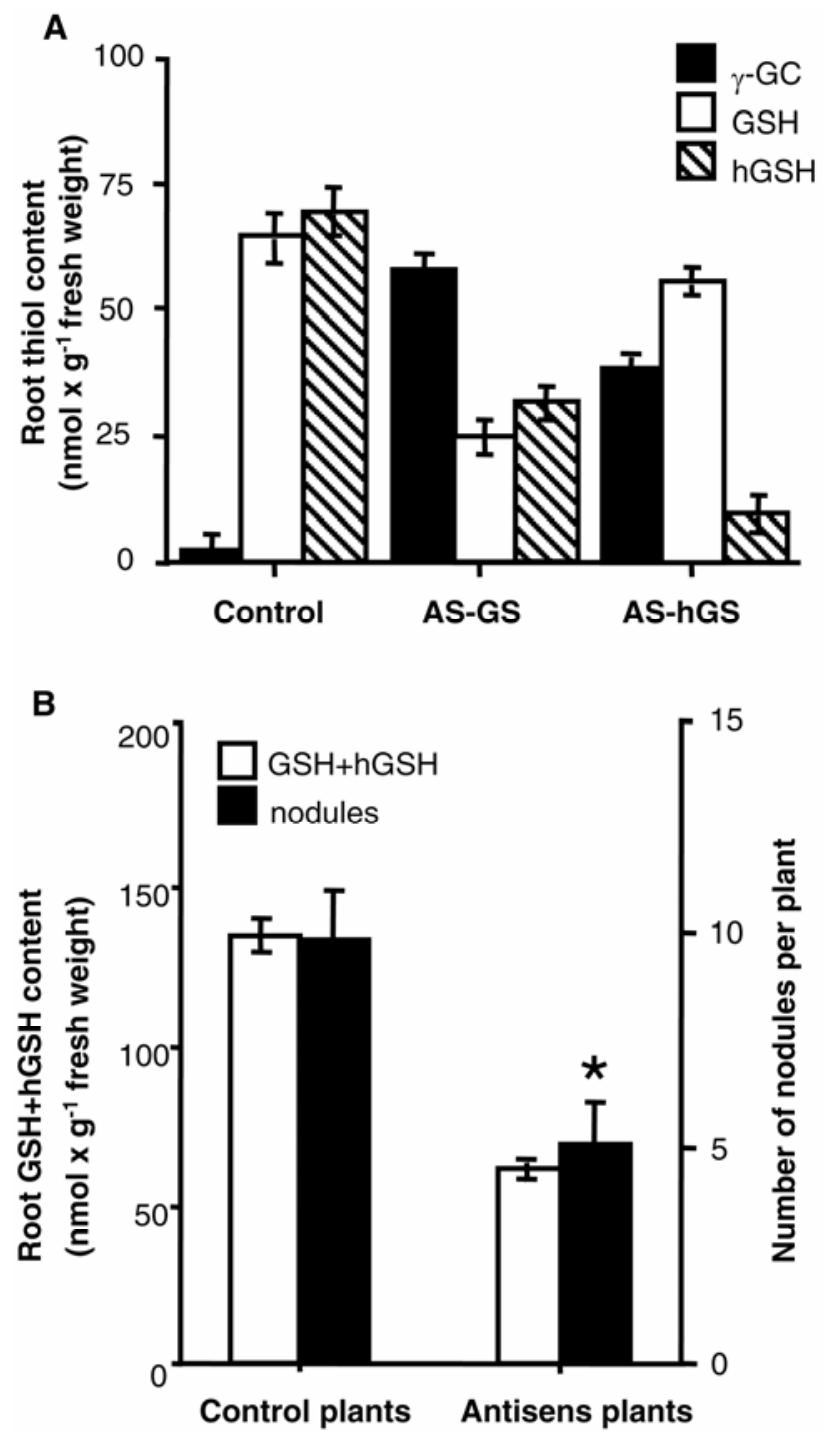

Fig. 2. Quantification of the reduced thiols and nodulation of Medicago truncatula transgenic roots. A, Glutathione (GSH), homoglutathione (hGSH), and $\gamma$-glutamylcysteine $(\gamma$-GC) content of nodulated roots of control plants transformed with empty vector pBI121 (control), plants transformed with the pBI121-ASGSHS construct (AS-GS), and plants transformed with the pBI121-AShGSHS construct (AS-hGS). B, Transgenic plants were inoculated with $S$. meliloti RCR2011, the number of nodules was counted 10 days after inoculation, and the GSH and hGSH pool then was quantified in nodulated roots.
AShGSHS. This diminution also was correlated with an increase in $\gamma$-GC concentration (Fig. 2A, plants AS-hGS). The 8 ASGSHS and 10 AShGSHS plants exhibited an overall $40 \%$ reduction in their root thiol content (GSH + hGSH) (Fig. 2B).

Transgenic roots were inoculated with $S$. meliloti strain RCR2011 and the number of nodules formed was assessed. The GSH- and hGSH-deficient plants showed a reduction in nodule number from an average of 10 nodules per root in the control plants to 5 nodules per root (Fig. 2B). Thus, in both transgenic and BSO-treated plants, GSH or hGSH deficiency diminishes the number of nodules, therefore demonstrating the important role of GSH and hGSH in the nodulation process.

\section{GSH and hGSH deficiency alters the formation} of nodule without affecting the infection process.

To analyze the implication of GSH and hGSH in nodule formation, the number of young developing nodules was measured in control and in GSH- and hGSH-deficient plants 4 days after inoculation. The number of nascent nodules was significantly lower in BSO-treated plants than in control plants (Fig. $3)$. In parallel, the expression of the early nodulin genes enod12 (Pichon et al. 1992; Scheres et al. 1990) and enod40 (Charon et al. 1997, 1999) was investigated in GSH- and hGSH-deficient plants by RNA gel blot hybridization (Fig. 4A). In control plants, expression of Mtenod12 was detected 4 days postinoculation, with a maximal expression observed 6 days postinoculation. In GSH- and hGSH-deficient plants, the level of expression of Mtenod12 was four times lower than in control plants 6 days postinoculation (Fig. 4B). Similarly, the induction of Mtenod40 expression observed in inoculated control plants was completely abolished in the inoculated GSHand hGSH-deficient plants. Thus, GSH or hGSH deficiency results in a reduction in the number of developing nodules which is confirmed by the diminution of the expression of genes involved in the morphogenetic and organogenetic plant responses.

In order to determine whether GSH or hGSH deficiency modified the infection efficiency, the average number of infection events per plant was estimated in control and GSH- and hGSH-deficient plants 4 days after inoculation with $S$. meliloti

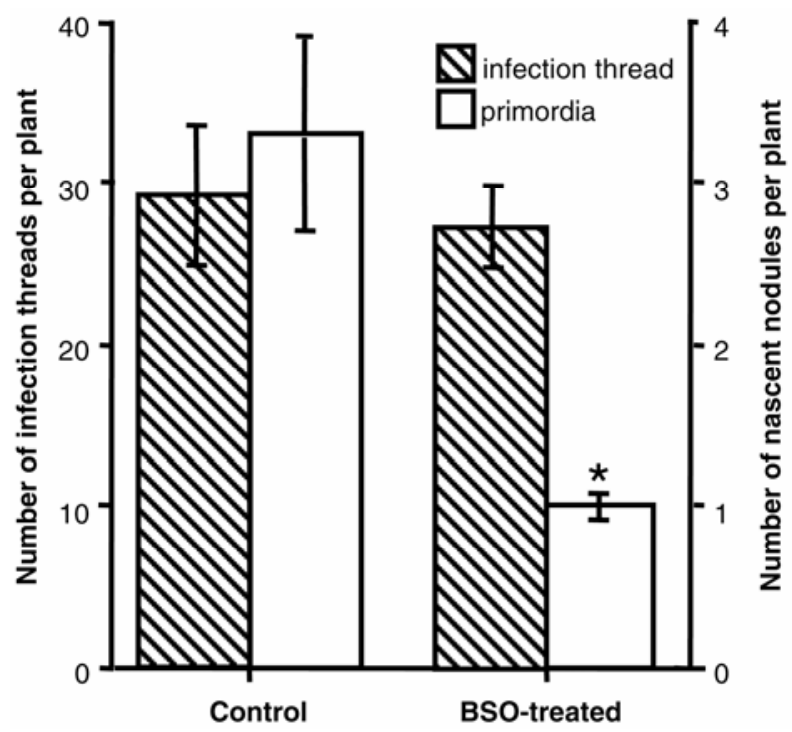

Fig. 3. Analysis of the number of infection events and nascent nodules in glutathione- and homoglutathione-deficient plants inoculated with Sinorhizobium meliloti. Plants were grown on modified Farhaeus medium (control) and modified Farhaeus medium containing $0.1 \mathrm{mM}$ L-buthionine-[S-R]-sulfoximine (BSO) for 1 week and inoculated with $S$. meliloti RCR2011. The number of infection threads and microscopic nodule primordia was assessed 4 days postinoculation; * indicates difference $(P<0.01)$ 
RCR2011 (pXLGD4). This strain constitutively expresses lacZ, allowing the visualization of the bacteria in planta following staining. No significant difference was observed in the number of infection events between the control and the BSOtreated plants (Fig. 3). To further confirm that BSO treatment did not modify the infection process, expression of the Rhizobium-induced peroxidase gene ripl, which coincides with early infection events (Cook et al. 1995), was monitored during the $48 \mathrm{~h}$ following infection (Fig. 5A and B). Uninoculated BSO-treated and control plants showed similar levels of rip1 expression. Moreover, the induction of ripl by S. meliloti infection was similar in control and BSO-treated plants. Taken together, these results show that physiological and molecular markers of the early steps of infection are not altered by GSH or hGSH deficiency.

\section{DISCUSSION}

Symbiosis establishment relies on numerous molecular, cellular, and developmental changes in several cell layers of the root. Among these modifications, ions fluxes, membrane depolarization, and calcium spiking are associated with the early perception of Nod factors (Cullimore et al. 2001). Later, Nod factors induce changes in gene expression in different cell layers of the host root and with different temporal expression patterns. These modifications in gene expression are correlated to cellular and developmental modifications such as reorganization of the microtubular cytoskeleton and the formation of the nodule primordium (Timmers et al. 1999). In this study, we show for the first time that a reduction of the GSH and hGSH pool achieved by either pharmacological or genetic approaches dramatically affects nodule formation, indicating that GSH and hGSH are essential for proper development of the nodule tis- sues. The number of microscopic nodules observed 4 days postinoculation is three times lower in GHS- and hGSH-deficient plants than in control plants, suggesting that the early steps of nodule primordium formation are affected. The fact that there are fewer nodules in the BSO-treated plants is further confirmed by the strong reduction of the level of expression enod 40 and enod 12 which are expressed during nodule formation. The deficiency in GSH or hGSH did not modify the number of infection events, showing that the lower number of nodules is not connected to an early abortion of the plant-Rhizobium sp. interaction. The observation that ripl, a gene induced throughout the pre-infection period (Cook et al. 1995), is expressed at a similar level in control and GHS- and hGSHdeficient plants further strengthens this idea.

Complementation of the BSO-treated plants by GSH treatment results in the restoration of nodulation efficiency, showing that the reduction in the number of nodules is not linked to a BSO side effect. Deficiency in GSH or hGSH did not change the number of infection events or the expression of ripl, showing that the lower number of nodules is not linked to an unspecific general stress process as observed during ethylene treatment (Oldroyd et al. 2001).

A modification of the early steps of the infection process is not observed in GSH- or hGSH-deficient plants, suggesting that GSH or hGSH is playing a role in the latter step of the nodulation development. The GSH or hGSH deficiency could result in a lower number of successful cortical infections which would end in a lower number of nodules. On the other hand, the inhibition of nodule formation correlated to a diminution of the number of lateral roots suggests that GSH and hGSH deficiency could impair meristem formation. Lateral root and nodule initiation have common features (de Billy et al. 2001; Mathesius 2001; Roudier et al. 2003) and genetic

A

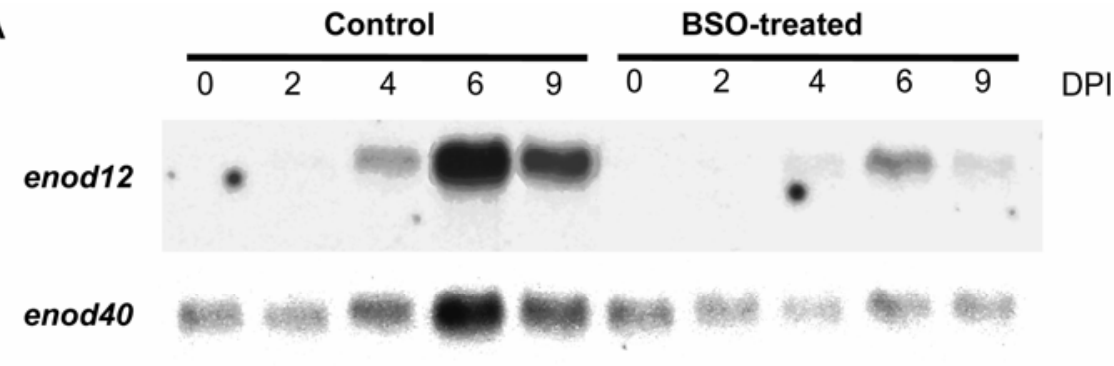

rRNA

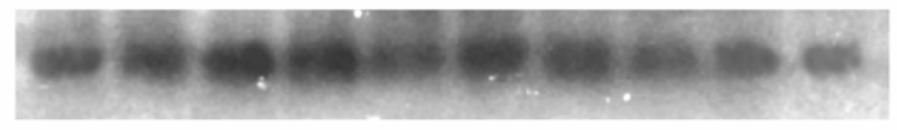

B

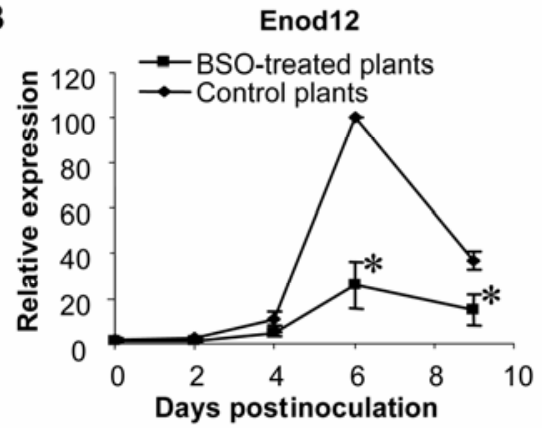

Enod40

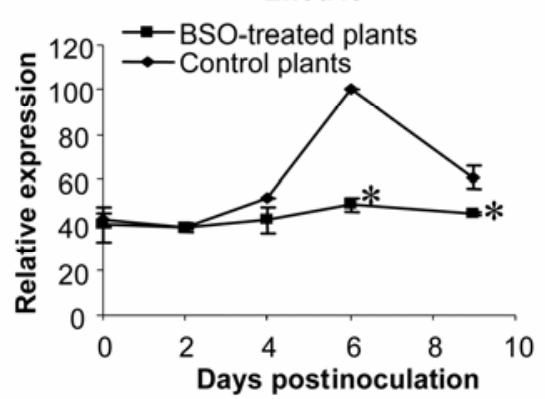

Fig. 4. Analysis of the expression of enod 12 and enod40 in glutathione- and homoglutathione-deficient plants inoculated with Sinorhizobium meliloti A, Plants were grown on modified Farhaeus medium (control) and modified Farhaeus medium containing 0.1 mM L-buthionine-[S-R]-sulfoximine (BSO) for 1 week and inoculated with $S$. meliloti RCR2011. Root tissue was collected at set times after inoculation. RNA gel blots were probed successively with Mtenod12 and Mtenod40 cDNAs and ribosomal RNA. B, Expression levels of Mtenod12 and Mtenod40 were standardized using the ribosomal RNA expression and quantified as percentage of the maximum level of expression of the corresponding gene; $*$ indicates significant difference (at least $P<0.05)$. 
mutants defective in both the autoregulation of nodulation and the lateral root formation have been obtained (Searle et al. 2003; Wopereis et al. 2000). In any case, our results indicate that GSH and hGSH have a crucial role in the nodulation process. The identification of molecular targets of GSH and hGSH during nodulation will bring significant insights on its roles during this process.

\section{MATERIALS AND METHODS}

Plant growth conditions, bacterial strains, and treatments.

M. truncatula ecotype Jemalong was used for all the experiments. Sterilized seedlings germinated for $48 \mathrm{~h}$ onto $0.5 \%$ agarose were plated onto modified Fahraeus medium (BoissonDernier et al. 2001) with 1.3\% agar and grown for 7 days before inoculation. Plants were germinated and grown either in the presence or absence of BSO (0.1 to $1 \mathrm{mM})$, GSH $(0.5 \mathrm{mM})$, and cadmium $(0.1 \mathrm{mM})$. Plants were grown in a growth chamber with a day and night temperature of $22^{\circ} \mathrm{C}$ and with a photoperiod of $16 \mathrm{~h}$. S. meliloti strain RCR2O11, expressing $\beta$-galactosidase (Penmetsa and Cook 1997) or yellow fluorescent protein (Stuurman et al. 2000), was grown in Luria broth medium in the presence of tetracycline at $10 \mu \mathrm{g} / \mathrm{ml}$ as selection marker. Bacteria were pelleted at $16,000 \times g$, washed two times, and resuspended in sterile water to give a final optical density at $600 \mathrm{~nm}$ of 0.1 . Plants were inoculated using the bacterial suspension at $300 \mu \mathrm{l} / \mathrm{plant}$.

\section{Assessment}

of infection events, nodulation, and nitrogen fixation.

Four days following inoculation, roots from five plants per treatment were fixed and stained as described by Boivin and associates (1990). Infection threads and blue spots of bacteria

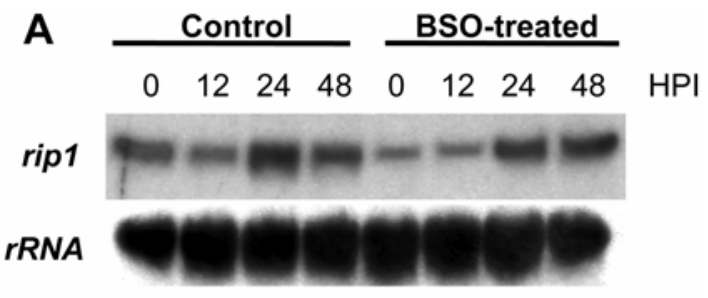

\section{B}

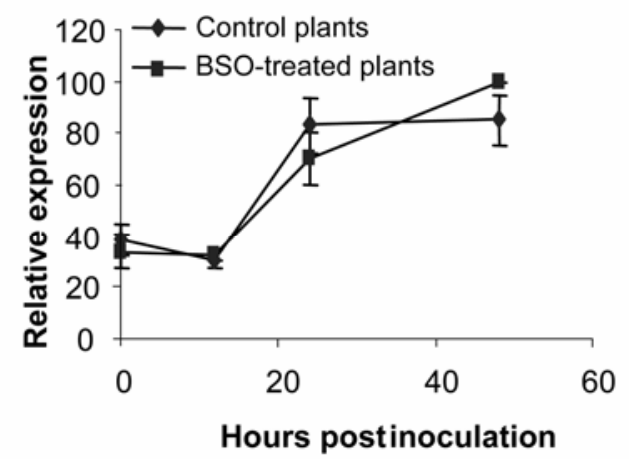

Fig. 5. Analysis of the expression of ripl in glutathione- and homoglutathione-deficient plants inoculated with Sinorhizobium meliloti. A, Plants were grown on modified Farhaeus medium (control) and modified Farhaeus medium containing $0.1 \mathrm{mM}$ L-buthionine-[S-R]-sulfoximine (BSO) for 1 week and inoculated with $S$. meliloti RCR2011. Root tissue was collected at set times after inoculation. RNA gel blots were probed successively with ripl cDNA and ribosomal RNA. B, Expression levels of ripl were standardized using the ribosomal RNA expression and quantified as percentage of the maximum level of expression. in the center of a shepherd's crook before infection thread formation were counted as infection events. The number of young developing nodules was numbered at the same stage. Three independent experiments were performed to establish the number of infection events. Nodules were counted on 15 to 25 plants per treatment at 7 and 10 days postinoculation. Three independent experiments were performed to determine the number of nodules. $\mathrm{N}_{2}$ nitrogen fixation activity was determined by $\mathrm{C}_{2} \mathrm{H}_{2}$ reduction as described by Hérouart and associates (1996).

\section{RNA analysis.}

RNA was extracted from $M$. truncatula according to Shirzadegan and associates (1991). For RNA gel blot analysis, RNA samples $(10 \mu \mathrm{g})$ were fractionated on $1.4 \%$ formaldehydeagarose gels, transferred onto Hybond $\mathrm{N}$ membrane (Amersham, Orsay, France), and hybridized according to standard protocols (Sambrook et al. 1989). Blots were hybridized with ripl, enod12, and enod40 cDNAs and ribosomal RNA hybridization served as RNA loading control. The membrane was exposed to X-ray film and was visualized on a BAS 1000 Phosphoimager (Fuji Photo Film Co., Tokyo). Quantifications were performed using the MacBas software (Fuji Photo Film Co.).

\section{GSH and hGSH determination.}

Thiols were extracted with perchloric acid, derivatized with monobromobimane, and quantified after separation on reversephase HPLC as described by Fahey and Newton (1987). Commercial GSH (Sigma, St. Quentin, France) and $\gamma$-EC (Promochem, Molsheim, France) were used as standards. The hGSH used as a standard was synthesized by Neosystem (Strasbourg, France).

\section{Construction of transgenic roots.}

Standard procedures were used for all recombinant DNA manipulations (Sambrook et al. 1989). A 1.1-kb fragment of GSHS (Frendo et al. 1999) and a 1.8-kb fragment of hGSHS (AF194422) of M. truncatula were subcloned using the XbaISalI sites present on pBluescript into the XbaI-SalI sites of the binary plasmid vector pBLTl 121 derived from plasmid pBI121/221 (Clontech, Palo Alto, CA, U.S.A.) in the antisense orientation relative to the $35 \mathrm{~S}$ promotor. The resulting plasmids, pBI121-ASGSHS and pBI121-AShGSHS, were introduced into Agrobacterium rhizogenes Arqual (Quandt et al. 1993) by the freeze thaw method (Hofgen and Willmitzer 1988) and transformants were selected by resistance to kanamycin. M. truncatula plants (Jemalong J5) were transformed with A. rhizogenes containing pBI121-ASGSHS and pBI121AShGSHS according to the protocol described by BoissonDernier and associates (2001). Control plants were transformed with $A$. rhizogenes containing the empty vector pBI121.

Selection of hairy roots took place 21 days after transformation, one transgenic root per plant was conserved, and the composite plants were transferred onto agar plates containing modified Fahraeus media. Plants were inoculated 3 days after transfer as described above.

At 10 days after inoculation, the number of nodules per transformed root was recorded and the roots then were harvested directly into liquid nitrogen. GSH and hGSH content of the roots then was determined as described above.

\section{Statistical analyses.}

All the data presented for the growth of the plants, the thiol concentrations, infection thread, and nodule numbers are given as means with the standard error. The significance of the results was tested using the Student's $t$ test. 


\section{ACKNOWLEDGMENTS}

This work was funded in part by the European Communities Improving Human Potential program (contract HPRN-CT-2000-00094); J. Harrison acknowledges the financial support provided through this contract. We gratefully acknowledge M. Delledone and E. Baudouin for critical reading of the manuscript, and P. Gamas and D. Barker for providing us with the $M$. truncatula enod 40 cDNA and the enod 12 cDNA, respectively. M. J. H. Jiménez was recipient of a Marie Curie postdoctoral fellowship from the European Communities Training and Mobility of Researchers program.

\section{LITERATURE CITED}

Becana, M., Dalton, D. A., Moran, J. F., Iturbe-Ormaetxe, I., Matamoros, M. A., and Rubio, M.C. 2000. Reactive oxygen species and antioxidants in legume nodules. Physiol. Plant. 109:372-381.

Boisson-Dernier, A., Chabaud, M., Garcia, F., Bécard, G., Rosenberg, C., and Barker, D. G. 2001. Agrobacterium rhizogenes-transformed roots of Medicago truncatula for the study of nitrogen-fixing and endomycorrhizal symbiotic associations. Mol. Plant-Microbe Interact. 14:695-700.

Boivin, C., Camut, S., Malpica, C. A., Truchet, G., and Rosenberg, C. 1990. Rhizobium meliloti genes encoding catabolism of trigonelline are induced under symbiotic conditions. Plant Cell 2:1157-1170.

Charon, C., Johansson, C., Kondorosi, A., and Crespi, M. 1997. enod40 induces dedifferentiation and division of root cortical cells in legumes. Proc. Natl. Acad. Sci. U.S.A. 94:8901-8906.

Charon, C., Sousa, C., Crespi, M., and Kondorosi, A. 1999. Alteration of enod40 expression modifies Medicago truncatula root nodule development induced by Sinorhizobium meliloti. Plant Cell 11:1953-1965.

Cohn, J., Bradley Day, R., and Stacey, G. 1998. Legume nodule morphogenesis. Trends Plant Sci. 3:105-110.

Cook, D., Dreyer, D., Bonnet, D., Howell, M., Nony, E., and Vandenbosh, K. 1995. Transient induction of a peroxidase gene in Medicago truncatula precedes infection by Rhizobium meliloti. Plant Cell 7:43-55.

Crespi, M. D., Jurkevitch, E., Poiret, M., d'Aubenton-Carafa, Y., Petrovics, G., Kondorosi, E., and Kondorosi, A. 1994. enod40, a gene expressed during nodule organogenesis, codes for a non-translatable RNA involved in plant growth. EMBO (Eur. Mol. Biol. Organ.) J. 13:5099-5112.

Cullimore, J. V., Ranjeva, R., and Bono, J. J. 2001. Perception of lipooligosaccharidic Nod factors in legumes. Trends Plant Sci. 6:24-30.

Dalton, D. A., Russell, S. A., Hanus, F. J., Pascoe, G. A., and Evans, H. J. 1986. Enzymatic reactions of ascorbate and glutathione that prevent peroxide damage in soybean root nodules. Proc. Natl. Acad. Sci. U.S.A. 83:3811-3815.

de Billy, F., Grosjean, C., May, S., Bennett, M., and Cullimore, J. V. 2001. Expression studies on AUX1-like genes in Medicago truncatula suggest that auxin is required at two steps in early nodule development. Mol. Plant-Microbe Interact. 14:267-277.

Dénarié, J., and Cullimore, J. 1993. Lipo-oligosaccharide nodulation factors: A new class of signalling molecules mediating recognition and morphogenesis. Cell 74:951-954.

Fahey, R. C., and Newton, G. L. 1987. Determination of low-molecularweight thiols using monobromobimane fluorescent labeling and highperformance liquid chromatography. Pages 85-96 in: Methods in Enzymology. W. B. Jakoby and O.W. Griffith, eds. Academic Press, San Diego, CA, U.S.A.

Frendo, P., Gallesi, D., Turnbull, R., Van de Sype, G., Hérouart, D., and Puppo, A. 1999. Localization of glutathione and homoglutathione in Medicago truncatula is correlated to a differential expression of genes involved in their synthesis. Plant J. 17:215-219.

Hérouart, D., Sigaud, S., Moreau, S., Frendo, P., Touati, D., and Puppo A. 1996. Cloning and characterisation of the katA gene of Rhizobium meliloti encoding a hydrogen peroxide-inducible catalase. J. Bacteriol. 178:6802-6809.

Hofgen, R., and Willmitzer, L. 1988. Storage of competent cells for Agrobacterium transformation. Nucleic Acids Res. 16:9877.

Journet, E. P., Pichon, M., Dedieu, A., de Billy, F., Truchet, G., and Barker, D. G. 1994. Rhizobium meliloti Nod factors elicit cellspecific transcription of the enod12 gene in transgenic alfalfa. Plant J. 6:241-249.

Klapheck, S. 1988. Homoglutathione: Isolation, quantification and occurrence in legumes. Physiol. Plant. 74:727-732.

Matamoros, M. A., Moran, J. F., Iturbe-Ormaetxe, I., Rubio, M. C., and Becana, M. 1999. Glutathione and homoglutathione synthesis in legume root nodules. Plant Physiol. 121:879-888.
Mathesius, U. 2001. Flavonoids induced in cells undergoing nodule organogenesis in white clover are regulators of auxin breakdown by peroxidase. J. Exp. Bot. 52:419-426.

May, M. J., Vernoux, T., Leaver, C., Van Montagu, M., and Inzé, D. 1998. Glutathione homeostasis in plants: Implications for environmental sensing and plant development. J. Exp. Bot. 49:649-667.

Mylona, P., Pawlowski, K., and Bisseling, T. 1995. Symbiotic nitrogen fixation. Plant Cell 7:869-885.

Noctor, G., Arisi, M.-C.M., Jouanin, L., Kunert, K. J., Rennenberg, H., and Foyer, C. H. 1998. Glutathione: Biosynthesis, metabolism and relationship to stress tolerance explored in transformed plants. J. Exp. Bot. 49:623-647.

Oldroyd, G. E. D., Engstrom, E. M., and Long, S. R. 2001. Ethylene inhibits the nod factor signal transduction pathway of Medicago truncatula. Plant Cell 13:1835-1849.

Penmetsa, R. V., and Cook, D. R. 1997. A legume ethylene-insensitive mutant hyperinfected by its rhizobial symbiont. Science 275:527-530.

Pichon, M., Journet, E. P., Dedieu, A., de Billy, F., Truchet, G., and Barker, D. G. 1992. Rhizobium meliloti elicits transient expression of the early nodulin gene ENOD12 in the differentiating root epidermis of transgenic alfalfa. Plant Cell 4:1199-1211.

Quandt, H.-J., Pühler, A., and Broer, I. 1993. Transgenic root nodules of Vicia hirsuta: A fast and efficient system for the study of gene expression in indeterminate-type nodules. Mol. Plant-Microbe Interact. 6:699706.

Roudier, F., Fedorova, E., Lebris, M., Lecomte, P., Gyorgyey, J., Vaubert, D., Horvath, G., Abad, P., Kondorosi, A., and Kondorosi, E. 2003. The Medicago species A2-type cyclin is auxin regulated and involved in meristem formation but dispensable for endoreduplication-associated developmental programs. Plant Physiol. 131:1091-103.

Sambrook, J., Fritsch, E. F., and Maniatis, T. A. 1989. Molecular Cloning: A Laboratory Manual, 2nd ed. Cold Spring Harbor Laboratory Press, Cold Spring Harbor, NY.

Sanchez-Fernandez, R., Fricker, M., Corben, L. B., White, N. S., Sheard, N., Leaver, C. J., Van Montagu, M., Inzé, D., and May, M. J. 1997. Cell proliferation and hair tip growth in the Arabidopsis root are under mechanistically different forms of redox control. Proc. Natl. Acad. Sci. U.S.A. 94:2745-2750.

Scheres, B., van de Wiel, C., Zalensky, A., Horvath, B., Spaink, H., van Eck, H., Zwartkuis, F., Wolters, A.-M., Gloudemans, T., van Kammen, A., and Bisseling, T. 1990. The ENOD12 gene product is involved in the infection process during pea-Rhizobium interaction. Cell 60:281294.

Searle, I. R., Men, A. E., Laniya, T. S., Buzas, D. M., Iturbe-Ormaetxe, I., Carroll, B. J., and Gresshoff, P. M. 2003. Long-distance signaling in nodulation directed by a CLAVATA1-like receptor kinase. Science 299:109-112.

Shirzadegan, M., Christie, P., and Seemann, J. R. 1991. An efficient method for isolation of RNA from tissue cultured plant cells. Nucleic Acids Res. 19:6055.

Stuurman, N., Bras, C. P., Schlaman, H. R., Wijfjes, A. H., Bloemberg, G., and Spaink, H. P. 2000. Use of green fluorescent protein color variants expressed on stable broad-host-range vectors to visualize rhizobia interacting with plants. Mol. Plant-Microbe Interact. 13:1163-1169.

Timmers, A. C., Auriac, M. C., and Truchet, G. 1999. Refined analysis of early symbiotic steps of the Rhizobium-Medicago interaction in relationship with microtubular cytoskeleton rearrangements. Development 126:3617-3628.

Vanacker, H., Carver, T. L. W., and Foyer, C. H. 2000. Early $\mathrm{H}_{2} \mathrm{O}_{2}$ accumulation in mesophyll cells leads to induction of glutathione during the hyper-sensitive response in the barley-powdery mildew interaction. Plant Physiol. 123:1289-1300.

Vasse, J., de Billy, F., and Truchet, G. 1993. Abortion of infection during the Rhizobium meliloti-alfalfa symbiotic interaction is accompanied by a hypersensitive reaction. Plant J. 4:555-566.

Vernoux, T., Wilson, R. C., Seeley, K. A., Reichheld, J. P., Muroy, S., Brown, S., Maughen, S. C., Cobbett, C. S., Van Montagu, M., and Inzé, D. 2000. The ROOT MERISTEMLESS1/CADMIUM SENSITIVE 2 gene defines a glutathione dependent pathway involved in the initiation and maintenance of cell division during postembryonic root development. Plant Cell 12:97-110.

Wingate, V. P. M., Lawton, M. A., and Lamb, C. J. 1988. Glutathione causes a massive and selective induction of plant defense genes. Plant Physiol. 87:206-210.

Wopereis, J., Pajuelo, E., Dazzo, F. B., Jiang, Q., Gresshoff, P. M., De Bruijn, F. J., Stougaard, J., and Szczyglowski, K. 2000. Short root mutant of Lotus japonicus with a dramatically altered symbiotic phenoltype. Plant J. 23:97-114. 